\title{
Use of Different Antibiotic Combinations against Fluoroquinolone-Resistant Salmonella enterica from Humans in Egypt
}

\author{
Abeer A. Rushdy, Feriala A. Abu Sef, Mona I. Mabrouk*, \\ Zeinab H. Kheiralla, S. M. Abd El-All* and Neveen M. \\ Saleh* \\ Botany Department, Faculty of Women for Arts, Science \& \\ Education, Ain Shams University and *Microbiology \\ Department, National Organization for Drug Control and \\ Research (NODCAR), Cairo, Egypt.
}

\begin{abstract}
7. MERGENCE of antibiotic resistance by pathogenic Salmonella spp. is a worldwide problem. Antibiotic combination was used as a clinical cure to solve the problem. Over one and a half years, one hundred gastroenteritis bacterial pathogens were collected from three Egyptian hospitals from fecal and blood sources. 58\% Salmonella isolates were purified and identified using phenotyping and serotyping techniques. Out of the 58\% Salmonella spp., 41.4\% represented $S$. Typhimurium, 27.6\% S. Enteritidis, 5.2\% S. Typhi, 3.4 \% S. Paratyphi A, $3.4 \%$ S. Paratyphi B and $19.0 \%$ other Salmonella. A total of 36 (62\%) out of 58 Salmonella spp. were fluroquinolone resistant by disk diffusion method. Resistance of five Salmonella strains to the fluroquinolone group was confirmed by MICs values. The level of these values was from $32->512 \mu \mathrm{g} / \mathrm{ml}$, which is higher than those recommended by CLSI. Seventy-five combined microtitre checkerboards were performed on the five fluroquinolone multiresistant Salmonella strains to assess the potential for combination therapy. No antagonism was observed with any combination. Synergy and additivity were achieved with $41.4 \%$ and $58.6 \%$, respectively. Time-kill synergy was more often seen at $24 \mathrm{hr}$. There is $100 \%, 50 \%$ and $40 \%$ agreement between time-kill and checkerboard results for three Salmonella strains. Resistant Salmonella has increased in Egypt. Fluroquinolone combination with $\beta$-lactams (gentamycin, amikacin) and aminoglycosides (cefotaxime) were effective in the treatment of resistant Salmonella Typhimurium, Enteritidis and Typhi.
\end{abstract}

Keywords: Salmonella enterica, Antibiotic combination, Antibiotic resistance, Fluoroquinolone.

Salmonella spp. are important clinical pathogens, causing Salmonella infections among humans and animals. Infections due to Salmonella enterica include enteric or typhoid fevers, caused by S. enterica serovar Typhi and S. enterica serovar Paratyphi, and salmonellosis caused by a large number of non-typhodial Salmonella (NTS) such as Salmonella Typhimurium, and Salmonella enterica serovar Enteritidis. S. enterica serovar Typhi and S. enterica serovar Paratyphi are human-restricted in their epidemiology and highly adapted in their 
pathogenesis (Gordon, 2008). Animals are the main reservoirs for NTS. The transmission of this microorganism occurs by the consumption of inadequately cooked or pasteurized foods of animal origin, including poultry, beef, fish, eggs, and dairy products. The incidence of human salmonellosis varies with geographic, socioeconomic and environmental factors (AL-Dawodi et al., 2012).

Salmonellosis and typhoid fever remain important public health problems worldwide (Ayana \& Surekha, 2008). Although antibiotics are not usually recommended for Salmonella gastroenteritis, they are recommended for invasive Salmonella infections, such as septicemia and meningitis that are common in infants, elderly and immunocompromised patients. Up to a decade ago, in many countries, conventional $1^{\text {st }}$-line antimicrobial agents, such as ampicillin, chloramphenicol, and sulfamethoxazole-trimethoprim, were the drugs of choice for the treatment of life-threatening Salmonella infections and still remain the main therapeutic drugs of choice in most African countries with poor resources. However, in the past two decades, isolation of multidrug-resistant Salmonella spp. has been reported from many parts of the world (Wedel et al., 2005). So, fluoroquinolones have become the $1^{\text {st }}$-line drugs for the treatment of lifethreatening salmonellosis and typhoid fever, but with treatment failures due to multidrug-resistant strains (Hakanen et al., 2001; Hirose et al., 2002; Baucheron et al., 2004 and Lunguya et al., 2013). Treatment of the latter with combination therapy, using two or more antibacterial agents, has become commonplace (Rybak \& McGrath, 1996).

Two of the most widely used in vitro methodologies to assess drug-drug interactions are the checkerboard minimum inhibitory concentration (MIC) technique, yielding the fractional inhibitory concentration index (FICI) and timekill kinetics (Rybak \& McGrath, 1996 and White et al., 1996). The checkerboard MIC method is prone to error and by necessity, its results are often confirmed with the more dynamic interaction provided by the time-kill kinetic study format (Cappelletty \& Rybak, 1996 and Jacqueline et al., 2005). The present study evaluates the effect of two combinations; fluoroquinolone with $\beta$ lactams and fluoroquinolone with aminoglycosides, against antibiotic resistant typhodial and non-typhodial clinical Salmonella isolates in Egypt.

\section{Clinical sitting}

\section{Materials and Methods}

Samples for the present study were obtained from July 2008 through December 2009 from microbiological laboratories of three government hospitals in Cairo. A total of one-hundred bacterial isolates; sixty from Abo El-Reesh Hospital for children, twenty-five from El-Hommiate Hospital and fifteen from El-Demerdash Hospital, were used in this study. Clinical isolates were collected from fecal and blood samples of patients with proven acute gastroenteritis, enteric fever, septicemia and bacteremia. 
Purification and Identification of Salmonella isolates

The morphology of colonies was observed by optical microscope, a single colony of expected bacteria (according to cell morphology) was picked and inoculated to the fresh agar plates. The purified colonies were obtained by repeated streaking of the single colony on fresh agar plates and their morphology was recorded as the basis for classification.

Pure bacterial isolates were identified using microbiological standard methods; selective and differential media (Brenner \& Farmer, 2004 and Thompson \& Miller, 2003). Confirmation of putative Salmonella isolates was performed by biochemical reaction and serological method using Salmonella $\mathrm{O}$ antisera polyvalent slide agglutination tests (Demka, Sejken, Co., LTD, Tokyo, Japan) (Table 1). The pure isolates were also further grouped into serogroup A, serogroup B or serogroup D Salmonella by the use of slide agglutination tests for antiserum factors (O) then tested to flagella $(\mathrm{H})$ antiserum phase I \& II according to Kauffman-White serotyping scheme (Popoff \& LeMinor, 1997 and Popoff, 2001).

TABLE 1. Method of Salmonella identification.

\begin{tabular}{|c|c|c|c|c|}
\hline Method & Control & \multicolumn{3}{|c|}{ Salmonella reaction } \\
\hline \multicolumn{5}{|c|}{ 1. Selective media } \\
\hline MacConky agar & Reddish orange & \multicolumn{3}{|c|}{ Coloreless } \\
\hline Salmonella /Shigella agar & Red-orange & \multicolumn{3}{|c|}{ Transparent with black center } \\
\hline Brilliant green agar & Orange-brown & \multicolumn{3}{|c|}{ Red } \\
\hline Bismuth sulfite agar & $\begin{array}{c}\text { Light grey-green to } \\
\text { medium green } \\
\text { Opaque }\end{array}$ & $\begin{array}{l}\text { black w/metallic } \\
\text { sheen }(S . \text { Typhi) }\end{array}$ & \multicolumn{2}{|c|}{$\begin{array}{c}\text { black or greenish-grey, } \\
\text { may have sheen } \\
(S . \text { Typhimurium })\end{array}$} \\
\hline $\begin{array}{l}\text { Xylose Lysine } \\
\text { Deoxycholate agar }\end{array}$ & Red & \multicolumn{3}{|c|}{ Red with black center } \\
\hline \multicolumn{5}{|c|}{ 2. Biochemical reaction } \\
\hline \multirow{2}{*}{$\begin{array}{l}\text { Motility Indole } \\
\text { Ornithine }\end{array}$} & \multirow[t]{2}{*}{ Purple, semi-solid. } & Motility & Indol & $\begin{array}{c}\text { Orithinine } \\
\text { decarboxylation }\end{array}$ \\
\hline & & $+\mathrm{ve}$ & -ve & $+\mathrm{ve}$ \\
\hline \multirow[t]{2}{*}{ Lysine iron agar } & \multirow[t]{2}{*}{ Purple } & $\begin{array}{c}\text { Lysine } \\
\text { decarboxylat } \\
\text { ion BUTT } \\
\end{array}$ & $\begin{array}{c}\text { Lysine } \\
\text { deamination } \\
\text { Slant } \\
\end{array}$ & $\begin{array}{c}\mathrm{H}_{2} \mathrm{~S} \\
\text { Apex of slant }\end{array}$ \\
\hline & & +ve Purple & -ve Purple & +ve black \\
\hline Simmons Citrate agar & Forest green & & Blue & \\
\hline \multirow{2}{*}{$\begin{array}{ll}\text { Methyl } & \text { Red-Voges- } \\
\text { Proskauer } & \end{array}$} & \multirow{2}{*}{ Light amber, clear } & \multicolumn{3}{|c|}{ +ve Bright red color (MR) } \\
\hline & & \multicolumn{3}{|c|}{-ve reaction (VP) } \\
\hline \multirow{3}{*}{ Triple Sugar Iron agar } & \multirow{3}{*}{ Red } & Slant/Butt & Gas & $\mathrm{H}_{2} \mathrm{~S}$ (black) \\
\hline & & Red/Yellow & $\begin{array}{c}+ \text { ve for } \\
S . \text { Entritidies }\end{array}$ & $+\mathrm{ve}$ \\
\hline & & Red/Yellow & $\begin{array}{c}\text { - ve for } \\
\text { S.Typhimurium }\end{array}$ & + ve \\
\hline Urease & Yellow & & Yellow ( -ve react & ion) \\
\hline \multicolumn{5}{|c|}{ 3. Serology (agglutination test) } \\
\hline \multicolumn{2}{|c|}{ Somatic (O antisera) } & \multicolumn{3}{|c|}{$\begin{array}{c}\text { Polyvalent O I,II,III } \\
\text { Serogroup A,B,C and factors }\end{array}$} \\
\hline \multicolumn{2}{|c|}{ Flagella ( $\mathrm{H}$ antisera) } & \multicolumn{3}{|c|}{ Phase I \&II } \\
\hline \multicolumn{5}{|c|}{ Virulance (Vi antisera) } \\
\hline
\end{tabular}

Egypt. J.Microbiol. 48 (2013) 
Antimicrobial susceptibility testing

Fifty-eight Salmonella spp. were obtained from 100 isolates and were screened for resistance to antimicrobial agents by disc diffusion method on Mueller-Hinton agar using commercial antibiotic disks including the aminoglycosides group [gentamycin $(\mathrm{GN})(10 \mu \mathrm{g})$ and amikacin $(\mathrm{AK})(30 \mu \mathrm{g})$ ], $\beta$-lactams group [ampicillin (AMP) $(10 \mu \mathrm{g})$, ampicillin/sulbctam (SAM) $(20 \mu \mathrm{g})$, amoxicillin/clavulinic acid (AMC) $(30 \mu \mathrm{g})$, piperacillin (PRL) $(100 \mu \mathrm{g})$, piperacillin/tazbactam (TZP) $(110 \mu \mathrm{g})$, cefotaxime (CTX) $(30 \mu \mathrm{g})$, ceftriaxone (CRO) $(30 \mu \mathrm{g})$, ceftazidime (CAZ) $(30 \mu \mathrm{g})$, cefepime (FEP) $(30 \mu \mathrm{g})$, impenem (IMP) $(10 \mu \mathrm{g})$, aztroname (ATM) $(30 \mu \mathrm{g})]$, phenicols [chloramphenicol (C) $(30 \mu \mathrm{g})$ ], sulfadrugs group [sulfamethoxazoletrimethoprim (SXT) $(25 \mu \mathrm{g})]$ and fluoroquinolones group [ nalidixic acid (NA) $(30 \mu \mathrm{g})$, ciprofloxacin(CIP) $(5 \mu \mathrm{g})$, levofloxacin (LEV) $(5 \mu \mathrm{g})$, ofloxacin (OFX) (5 $\mu \mathrm{g}) \&$ norfloxacin (NOR) $(30 \mu \mathrm{g})]$ (Oxoid, UK). The break points used were according to the interpretative criteria recommended by Clinical and Laboratory Standards Institute (CLSI, 2008).

Determination of minimum inhibitory concentrations (MICs)

Standard powder forms of ciprofloxacin, levofloxacin, ofloxacin (Eipico), cefotaxime (Aventis Pharma), ceftazidime (GlaxoSmithKline), cefepime (Bristol-Myers Squibb), amikacin (Bristol-Myers Squibb) and gentamycin (Schering-Plough) were used. The MICs of these antibiotics were determined by the broth microdilution method according to CLSI (2008) at concentration range $0.1-512 \mu \mathrm{g} / \mathrm{ml}$ for each drug immediately prior to testing. Mueller-Hinton broth (LAB M, USA) was used as the culture medium. Escherichia coli ATCC 25922 and Salmonella Typhimurium ATCC 14028 were used as control strains for evaluation of antibiotic potency.

\section{Evaluation of antibiotics synergy}

Two different methods were compared for the determination of synergy: checkerboard and time-kill method.

\section{Checkerboard method}

The dynamic checkerboard method was performed to evaluate the interaction of fluoroquinolones in combination with $\beta$-lactams and aminoglycosides, each at a time, against Salmonella isolates. The concentration range of each antibiotic combination ranged from $1 / 4$ to $1 / 5$ concentrations of MIC up to $2 \mathrm{X}$ MIC dilution. Organisms and antibiotic concentrations were prepared as described for the MIC determination using microtitre plates. To evaluate the effect of the combinations, the fractional inhibitory concentration (FIC) index was calculated for each antibiotic in each combination using the following formula:

FIC index $=\mathrm{FIC}_{\mathrm{A}}+\mathrm{FIC}_{\mathrm{B}}$

where: $\mathrm{FIC}_{\mathrm{A}}=\mathrm{MIC}$ of drug $\mathrm{A}$ in combination/MIC of drug $\mathrm{A}$ alone

$\mathrm{FIC}_{\mathrm{B}}=\mathrm{MIC}$ of drug $\mathrm{B}$ in combination/MIC of drug B alone

Synergy was defined as an FIC index of $\leq 0.5$. Additive or indifferent was defined as an FIC index of $>0.5$ but of $\leq 4.0$. Antagonism was defined as an FIC index of > 4.0 (White et al., 1996 and Satish et al., 2005).

Egypt. J. Microbiol. 48 (2013) 
Time-kill curve

Drug concentrations used for time-kill assays were based on three criteria: (i) Concentrations likely to produce synergy as seen in checkerboard testing; (ii) Concentrations those were not more than twice the MIC of each drug; (iii) Concentrations that were within clinically achievable serum levels for each drug Time-kill assays were performed in 10ml Mueller-Hinton broth (LAB M, USA). Each assay included a growth control tube with no antibiotic. The inoculum and antibiotic dilution were prepared as in MIC determination. For determination of viable counts, the surviving bacteria were counted after $0,3,6$ and $24 \mathrm{hr}$ postinoculation at $37^{\circ} \mathrm{C}$ by sub-culturing $100 \mu \mathrm{l}$ after serially dilution in saline solution $(0.9 \%)$ onto Mueller-Hinton agar plates in duplicate. Total bacterial count $\left(\log _{10} \mathrm{cfu} / \mathrm{ml}\right)$ was determined after $24 \mathrm{~h}$ of incubation at $37^{\circ} \mathrm{C}$. A bactericidal effect was defined as $\geq 3 \log _{10} \mathrm{cfu} / \mathrm{ml}$ decrease after $24 \mathrm{~h}$ of incubation compared to the size of the initial inoculum. Synergy was defined as a decrease in colony count of $\geq 2 \log _{10} \mathrm{cfu} / \mathrm{ml}$ with the combination compared to the count obtained with the most active single drug. Antagonism was defined as an increase in colony count of $\geq 2 \log _{10} \mathrm{cfu} / \mathrm{ml}$ with the combination compared to the count obtained with the most active single drug. Additive was defined as a change in colony count of $<10$ fold decrease in viable count at $24 \mathrm{~h}$ with the combination compared to the count obtained with the most active single drug (Eliopoulos \& Moellering, 1991; White et al., 1996 and Satish et al., 2005).

\section{Results}

\section{Distribution of Salmonella isolates}

During this study a total of 100 bacterial samples from enteric infections, during 18 months, were purified and identified. Out of the 100 isolates, $58 \%$ proved to be Salmonella by microscopy, selective and differential media and biochemical examination. Distribution of the 58 Salmonella isolates, were: 40 from Abo-El-Reesh Children Hospital, 15 from El-Hommiate Hospital and 3 from El-Demerdash Hospital. Out of the 58 Salmonella spp., 64\% were from males and $36 \%$ were from females, so incidence of infection was higher in male than in female, also the incidence of Salmonella infection was higher in children $(69 \%)$ than in adults $(31 \%)$ and stool was a higher source of infection $(81.1 \%)$ than blood $(18.9 \%)$.

\section{Identification of pure Salmonella isolates}

Out of the 58 Salmonella isolates, $24(41 \%)$ were Salmonella enterica serovar Typhimurium, 16 (28\%) were Salmonella enterica serovar Enteritidis, 3 (5\%) were Salmonella enterica serovar Typhi, 2 (3\%) were Salmonella enterica serovar Paratyphi A, 2 (3\%) were Salmonella enterica serovar Paratyphi B and $11(19 \%)$ were other serovar. The most common serotypes among Salmonella strains were the two non-typhodial, $S$. Typhimurium followed by $S$. Enteritidis. 
Antimicrobial susceptibility testing

The antibiotic resistance incidence rate in Salmonella Typhimurium was higher than in $S$. Enteritidis followed by $S$. Typhi and $S$. Paratyphi A \& B.

Out of the 58 Salmonella isolates, five multi-resistant Salmonella isolates were selected (Fig.1), these strains showed resistance to most tested antibiotics especially the fluoroquinolone group where Salmonella enterica serovar Typhimurium (S. Tm) (no. 7) was resistant to all tested 20 antibiotics; $S$. enterica serovar Enteritidis ( $S$. En) (no. 22), resistant to 19 antibiotics (except SXT); S. enterica serovar Typhimurium (S. Tm) (no. 54), resistant to 17 antibiotics (except PRL, TZP \& IMP from the $\beta$-lactams group) and $S$. enterica serovar Typhi (S. Ty) (no. 49), resistant to 17 antibiotics (except CTX,CAZ \& IMP from the $\beta$-lactams group); while $S$. enterica serovar Typhimurium $(S$. Tm) (no. 57) was resistant to 14 antibiotics (except AK from the aminoglycosides group, PRL, TZP, CRO, CAZ from the $\beta$-lactams group \& NOR from the fluoroquinolones group).

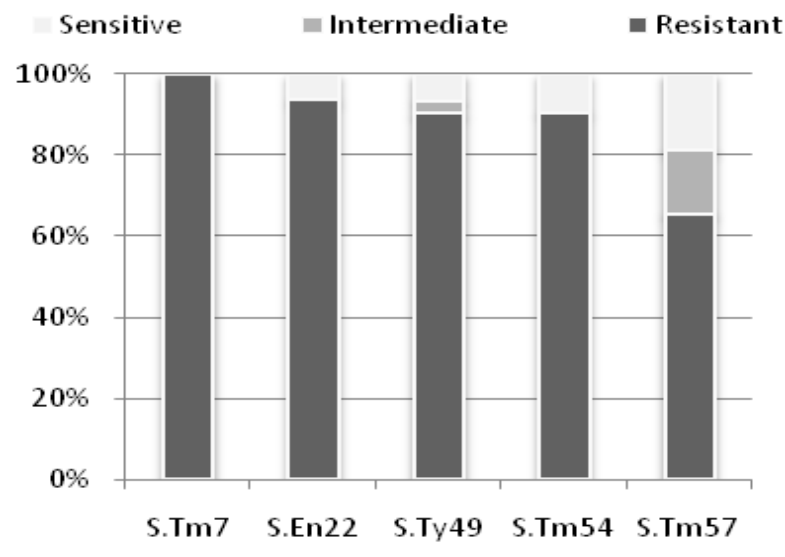

Salmonellastrains

Fig. 1. Antibiotic resistance of five multi-resistant Salmonella strains against 20 different antibiotics by disk diffusion method.

As presented in Table 2, the MIC for the five multi-resistant Salmonella isolates was tested and the data showed that $S$. Typhimurium (54) was the most resistan, t with MICs ranging from $128-512 \mu \mathrm{g} / \mathrm{ml}$; while $S$. Typhi (49) had the lowest MIC ranging from 16-128 $\mu \mathrm{g} / \mathrm{ml}$ for tested antibiotics. The MIC of ciprofloxacin for $S$. Typhimurium (57 and 54) was $512 \mu \mathrm{g} / \mathrm{ml}$ followed by $S$.Enteritidis (22) with $256 \mu \mathrm{g} / \mathrm{ml}$ then $S$. Typhimurium (7) with $64 \mu \mathrm{g} / \mathrm{ml}$ while $S$. Typhi (49) had the lowest MIC of $16 \mu \mathrm{g} / \mathrm{ml}$. 
TABLE 2. MIC of five multi-resistant Salmonella strains using microdilution method.

\begin{tabular}{|c|c|c|c|c|c|c|}
\hline \multirow{2}{*}{ Salmonella sp. } & \multirow[b]{2}{*}{ Antibiotics } & \multicolumn{5}{|c|}{$\mathrm{MIC}^{\mathrm{a}}(\mu \mathrm{g} / \mathrm{ml})$} \\
\hline & & S. Tm & $\begin{array}{c}S . \text { En } \\
22^{\mathrm{c}}\end{array}$ & $S .{ }_{49^{\mathrm{d}}}^{\mathrm{Ty}}$ & $\begin{array}{c}\text { S. Tm } \\
54^{\mathrm{b}}\end{array}$ & $\begin{array}{c}\text { S. Tm } \\
57^{\mathrm{b}}\end{array}$ \\
\hline \multirow{3}{*}{ Fluroquinolone } & Ciprofloxacin & 64 & 256 & 16 & $>512$ & 512 \\
\hline & Levofloxacin & 64 & 128 & 32 & $>512$ & 64 \\
\hline & Ofloxacin & 128 & 128 & 32 & $>512$ & 128 \\
\hline \multirow{3}{*}{$\beta$-lactam } & Cefotaxime & 512 & 512 & 128 & $>512$ & $>512$ \\
\hline & Ceftazidime & $>512$ & $>512$ & 64 & $>512$ & $>512$ \\
\hline & Cefipime & $>512$ & $>512$ & 64 & $>512$ & 512 \\
\hline \multirow{2}{*}{ Aminoglycoside } & Amikacin & 128 & 64 & 16 & 128 & 32 \\
\hline & Gentamycin & 512 & $>512$ & 32 & 256 & 16 \\
\hline
\end{tabular}

For the $\beta$-lactams group, the MICs were similarly high for all strains except S. Typhi (49) which had lower MICs than others. For the Aminoglycosides group, gentamycin had higher MICs than amikacin, except for $S$. Tm (57).

\section{Combination of antibiotics}

Table 3 summarizes the results of the checkerboards. of the 75 checkerboards, $41.3 \%$ were found to be synergistic according to FIC index and $58.6 \%$ additive for the test strains. There was no antagonism reported for any combination (Fig. 2).

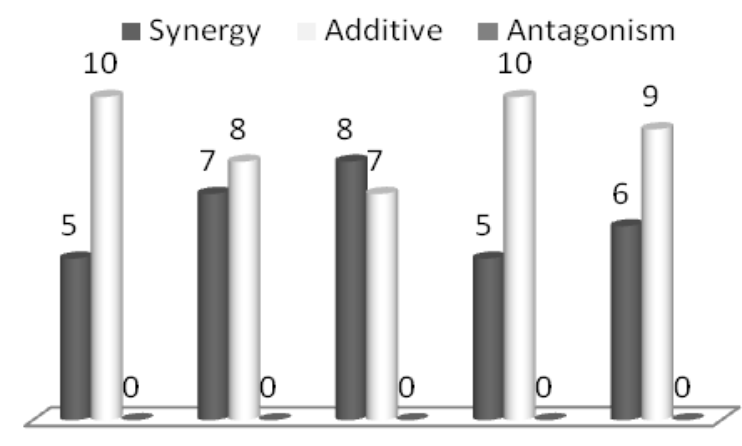

$\begin{array}{lllll}\text { S. Tm } 7 & \text { S.E } 22 & \text { S.Ty } 49 & \text { S. Tm } 54 & \text { S. Tm } 57\end{array}$

Salmonella isolates

Fig. 2. Checkerboard activity of five multidrug resistant Salmonella strains according to fractional inhibitory concentration (FIC) index. 
TABLE 3. Checkerboard of five multi-resistant Salmonella strains.

\begin{tabular}{|c|c|c|c|c|c|c|c|c|c|c|c|c|c|c|c|}
\hline \multirow{2}{*}{$\begin{array}{c}\text { Antibiotic } \\
\text { Combina- } \\
\text { tion }\end{array}$} & \multicolumn{3}{|c|}{ S. $\operatorname{Tm} 7$} & \multicolumn{3}{|c|}{ S. En 22} & \multicolumn{3}{|c|}{ S. Ty 49} & \multicolumn{3}{|c|}{ S. Tm 54} & \multicolumn{3}{|c|}{ S. Tm 57} \\
\hline & Conc. & FIC & Activity & Conc. & FIC & Activity & Conc. & FIC & Activity & Conc. & FIC & Activity & Conc. & FIC & Activity \\
\hline CIP/AK & $64 / 64$ & 1.50 & A & $32 / 16$ & 0.75 & A & $4 / 4$ & 0.50 & $S$ & $256 / 64$ & 1.50 & A & $64 / 16$ & 0.5 & S \\
\hline CIP/GN & $64 / 256$ & 1.50 & A & $16 / 128$ & 0.50 & S & $4 / 16$ & 0.50 & S & $256 / 256$ & 2.50 & A & $256 / 16$ & 1.5 & A \\
\hline CIP/CTX & $16 / 128$ & 0.25 & S & $8 / 128$ & 0.37 & S & $4 / 32$ & 0.50 & S & $256 / 64$ & 1.00 & A & $128 / 64$ & 0.37 & S \\
\hline CIP/CAZ & $128 / 256$ & 2.50 & A & $32 / 128$ & 1.50 & A & $4 / 8$ & 0.37 & $S$ & $256 / 512$ & 1.50 & A & $128 / 64$ & 0.37 & $S$ \\
\hline $\mathrm{CIP} / \mathrm{FEP}$ & $128 / 256$ & 2.50 & A & $8 / 128$ & 0.37 & $S$ & $4 / 8$ & 0.37 & $S$ & $256 / 256$ & 2.50 & A & $64 / 256$ & 0.62 & A \\
\hline OFX/AK & $16 / 32$ & 0.25 & S & $64 / 32$ & 1.50 & A & $8 / 4$ & 0.50 & S & $128 / 32$ & 0.50 & S & $64 / 32$ & 1.5 & A \\
\hline OFX/GN & $64 / 256$ & 1.00 & A & $64 / 128$ & 1.50 & A & $8 / 16$ & 0.75 & A & $128 / 64$ & 0.50 & $S$ & $32 / 4$ & 0.5 & $S$ \\
\hline OFX/CTX & $32 / 128$ & 0.25 & $S$ & $128 / 128$ & 1.25 & A & $16 / 64$ & 1.00 & A & $256 / 512$ & 1.50 & A & $64 / 128$ & 0.75 & A \\
\hline $\mathrm{OFX} / \mathrm{CAZ}$ & $64 / 256$ & 1.00 & A & $64 / 64$ & 1.00 & A & $16 / 16$ & 0.75 & A & $256 / 256$ & 1.00 & A & $32 / 256$ & 0.75 & A \\
\hline OFX/FEP & $32 / 256$ & 0.75 & A & $64 / 128$ & 0.75 & A & $16 / 16$ & 0.75 & A & $256 / 256$ & 1.50 & A & $32 / 16$ & 1.0 & A \\
\hline LEV/AK & $32 / 32$ & 0.75 & A & $32 / 16$ & 0.50 & $S$ & $16 / 8$ & 1.00 & A & $32 / 64$ & 0.50 & $S$ & $8 / 16$ & 1.0 & A \\
\hline LEV/GN & $16 / 128$ & 0.50 & $S$ & $16 / 64$ & 0.25 & $S$ & $8 / 16$ & 0.75 & A & $64 / 64$ & 0.25 & $S$ & $8 / 128$ & 0.92 & A \\
\hline LEV/CTX & $16 / 128$ & 0.50 & $S$ & $16 / 128$ & 0.50 & $S$ & $16 / 16$ & 0.37 & $S$ & $64 / 128$ & 0.37 & $S$ & $64 / 256$ & 0.37 & $S$ \\
\hline LEV/CAZ & $64 / 512$ & 2.00 & A & $16 / 128$ & 0.37 & $S$ & $16 / 8$ & 0.37 & $S$ & $128 / 256$ & 0.75 & A & $32 / 128$ & 0.75 & A \\
\hline LEV/FEP & $32 / 256$ & 1.00 & A & $64 / 128$ & 0.75 & A & $8 / 8$ & 0.75 & A & $128 / 256$ & 0.75 & A & $8 / 128$ & 0.37 & S \\
\hline
\end{tabular}

Checkerboard combination using microtitre method at $24 \mathrm{~h}$ incubation time. Conc, concentration. FIC, fractional inhibitory concentration. S, Synergy. A, Additive Aminoglycosides group [gentamycin (GN) and amikacin (AK) ]

Six of 18 checkerboards were found synergic by $\geq 2 \log _{10}$ decrease in killing curve as compared to the most active drug in combination at $24 \mathrm{~h}$. One of the boards was defined as synergy by these criteria at $3 \mathrm{~h}$, also one combination at $6 \mathrm{~h}$. One of the boards at 3 and $6 \mathrm{~h}$ was defined as synergy and also one at 3 and $24 \mathrm{~h}$ and 6 and $24 \mathrm{~h}$ were defined as synergy by these criteria against three resistant Salmonella isolates. Out of 18 checkerboards, twelve recorded synergic action as compared with the most active drug. Killing-curve for Salmonella 
isolates (no.7, $49 \& 54)$ showed 100\% (5/5), 50\% (4/8) and 40\% (2/5) agreement between the checkerboard and time-kill, respectively.

Time-kill results showed that ciprofloxacin combined with gentamycin for $S$.Typhi (49) and with cefotaxime for $S$. Typhimurium (7) achieved synergy action as represented in Fig. 5c and 3a .

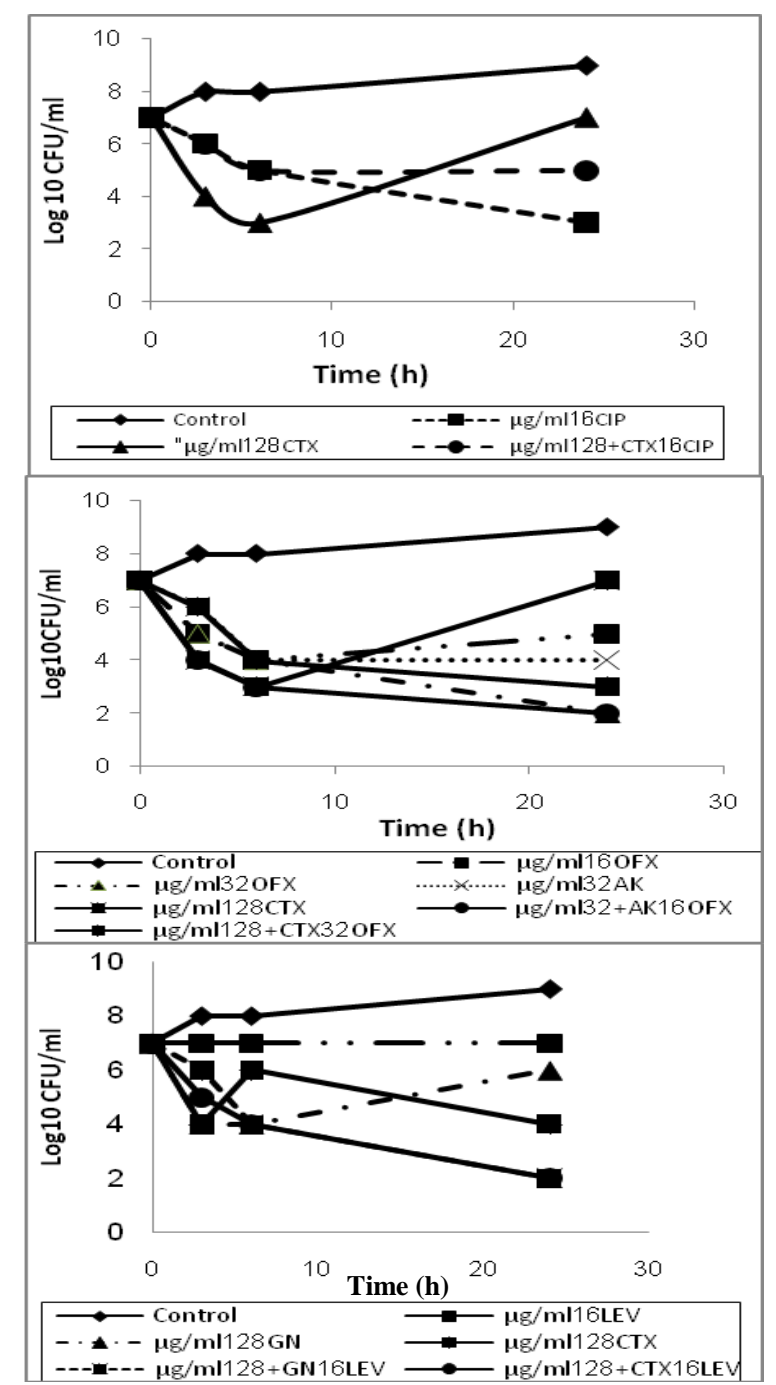

Fig. 3. Killing assay of Salmonella Typhimurium (S. Tm no. 7) at $0,3,6,24 \mathrm{~h}$ incubation time. a) Time kill assay of ciprofloxacin at $16 \mu \mathrm{g} / \mathrm{ml}+$ cefotaxime at $128 \mu \mathrm{g} / \mathrm{ml}$. b) Time kill assay of ofloxacin at $16 \mu \mathrm{g} / \mathrm{ml}+$ amikacin $32 \mu \mathrm{g} / \mathrm{ml}$ and ofloxacin at $32 \mu \mathrm{g} / \mathrm{ml}+$ cefotaxime at $128 \mu \mathrm{g} / \mathrm{ml}$. c) Time kill assay of levofloxacin at $16 \mu \mathrm{g} / \mathrm{ml}+$ gentamycin at $128 \mu \mathrm{g} / \mathrm{ml}$ and levofloxacin $16 \mu \mathrm{g} / \mathrm{ml}+$ cefotaxime $128 \mu \mathrm{g} / \mathrm{ml}$. 
Salmonella Typhimurium (7) killing-curve combination of ofloxacin with amikacin and cefotaxime also levofloxacin with gentamycin and cefotaxime showed synergistic action (Fig. 3b \& 3c). Killing-curve for $S$. Typhimurium (54) (Fig. 4a,b,c) represented antagonism when levofloxacin was combined with amikacin, gentamycin, and cefotaxime while when ofloxacin was combined with amikacin and gentamycin they had synergy action with $40 \%$ agreement with checkerboard .

Figure 5 a to 5 e show that synergistic action was achieved in combination of ciprofloxacin with amikacin and gentamycin, ofloxacin with amikacin and levofloxacin with cefotaxime for killing curve of $S$. Ty (49), while three time-kill showed additive reaction for ciprofloxacin with cefotaxime and ceftazidime and ciprofloxacin combined with cefepime had antagonism action.

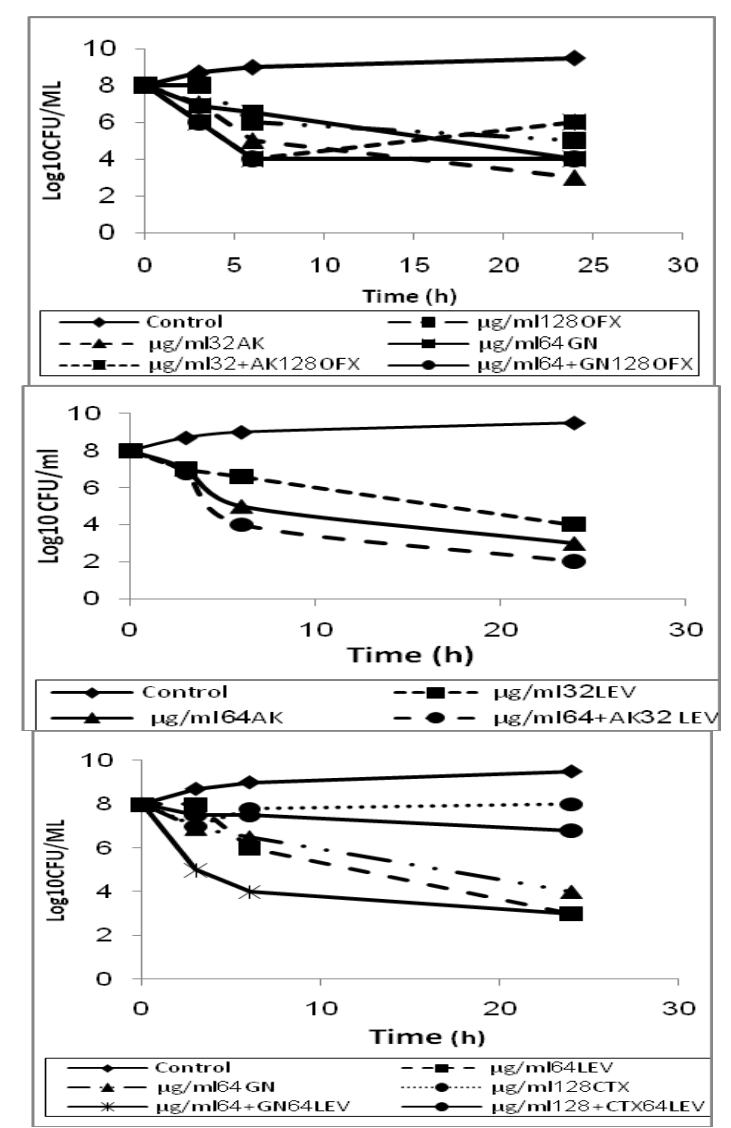

Fig. 4. Killing assay of Salmonella Typhimurium (S.Tm no. 54) at $0,3,6,24 \mathrm{~h}$ incubation time. a) Time kill assay of ofloxacin at $128 \mu \mathrm{g} / \mathrm{ml}+$ amikacin $32 \mu \mathrm{g} / \mathrm{ml}$ and ofloxacin at $128 \mu \mathrm{g} / \mathrm{ml}+$ gentamycin at $64 \mu \mathrm{g} / \mathrm{ml}$. b) Time kill assay of levofloxacin at $32 \mu \mathrm{g} / \mathrm{ml}$ +amikacin at $64 \mu \mathrm{g} / \mathrm{ml}$. c) Time kill assay of levofloxacin at $64 \mu \mathrm{g} / \mathrm{ml}+$ gentamycin at $64 \mu \mathrm{g} / \mathrm{ml}$ and levofloxacin at $64 \mu \mathrm{g} / \mathrm{ml}+$ cefotaxime at $128 \mu \mathrm{g} / \mathrm{ml}$.

Egypt. J. Microbiol. 48 (2013) 


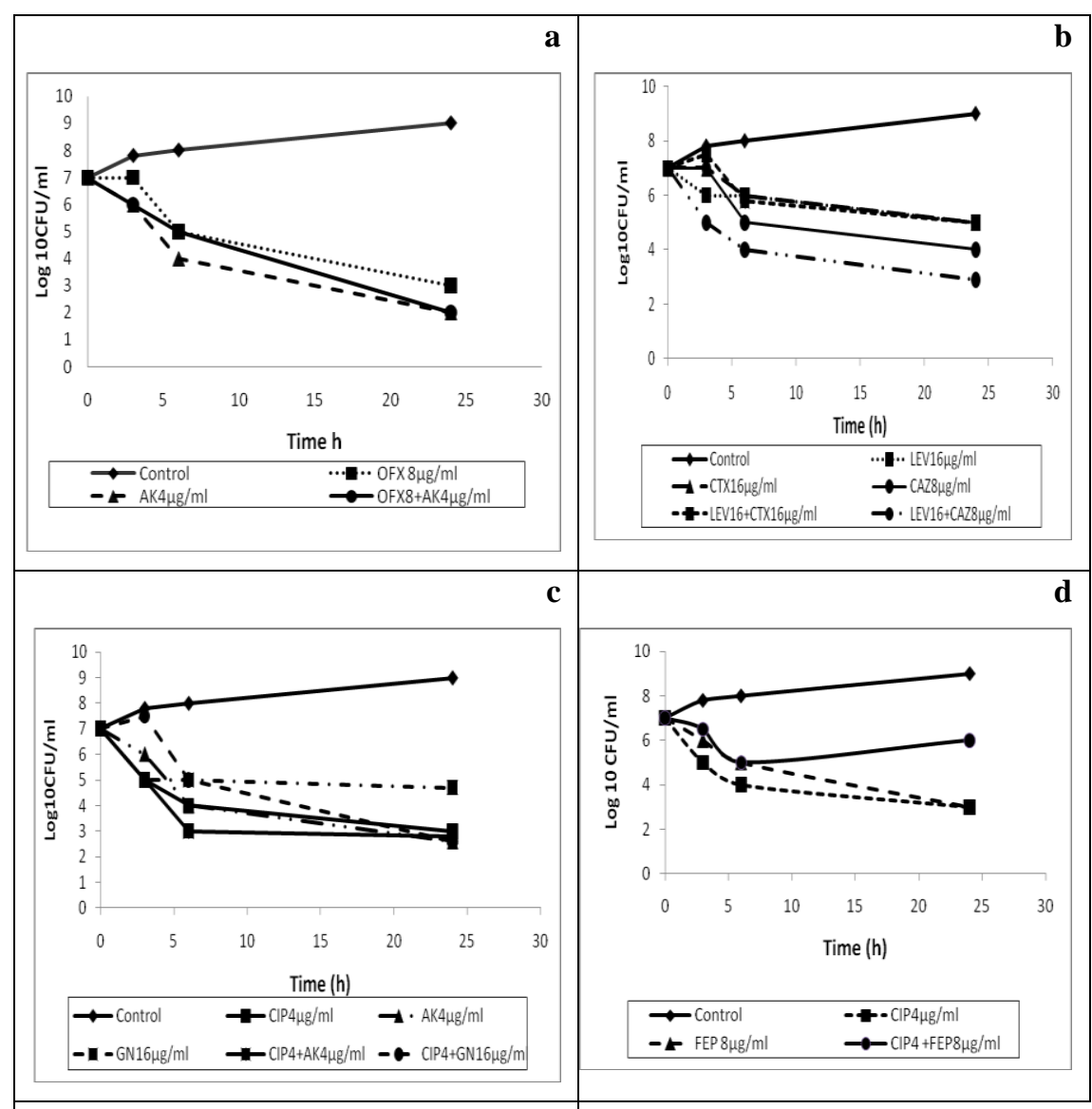

e $\quad$ Fig. 5. Killing assay of Salmonella Typhi (S. Ty no. 49) at $0,3,6,24 \mathrm{~h}$ incubation time. a) Time kill assay of ofloxacin at $8 \mu \mathrm{g} / \mathrm{ml}+$ amikacin at $4 \mu \mathrm{g} / \mathrm{ml}$. b) Time kill assay of levofloxacin at $16 \mu \mathrm{g} / \mathrm{ml}+$ cefotaxime $16 \mu \mathrm{g} / \mathrm{ml}$ and levofloxacin at $16 \mu \mathrm{g} / \mathrm{ml}+$ ceftazidime at $8 \mu \mathrm{g} / \mathrm{ml}$. c) Time kill assay of ciprofloxacin at $4 \mu \mathrm{g} / \mathrm{ml}+$ amikacin at $4 \mu \mathrm{g} / \mathrm{ml}$ and ciprofloxacin $4 \mu \mathrm{g} / \mathrm{ml}+$ gentamycin $16 \mu \mathrm{g} / \mathrm{ml}$. d) Time kill assay of ciprofloxacin at $4 \mu \mathrm{g} / \mathrm{ml}+$ cefepime $8 \mu \mathrm{g} / \mathrm{ml}$. e) Time kill assay of ciprofloxacin at $4 \mu \mathrm{g} / \mathrm{ml}$ + cefotaxime at $32 \mu \mathrm{g} / \mathrm{ml}$ and ciprofloxacin at $4 \mu \mathrm{g} / \mathrm{ml}+$ ceftazidime at $8 \mu \mathrm{g} / \mathrm{ml}$. 


\section{Discussion}

Bacterial enteropathogens account for gastroenteritis infections observed worldwide with Salmonella being the principal cause. The majority of Salmonella isolates from Egyptian hospitals are of $S$. Typhimurium and $S$. Enteritidis as non-typhoidal Salmonella and $S$. Typhi and, S. Paratyphi A, B as typhodial. Hakanen et al. (2006) reported that the countries of origin of nontyphodial Salmonella infections are most commonly Thailand with $34 \%$ of isolates, Egypt with $31 \%$ of isolates and Spain with $25 \%$ of isolates. The present study revealed that incidence of Salmonella in Egypt from July 2008 through December 2009, increased to $58 \%$ due to absence of sanitary measures regarding food habits. Aktas et al. (2007) stated that in Istanbul, Turkey 63\% of Salmonella spp. were identified as $S$. Enteritidis and $36 \%$ as $S$. Typhimurium.

Salmonella incidence in children is higher than in adults and stool was recorded as the main source of infection compared to blood source. Marimón et al. (2004) reported that $53 \%$ of Salmonella isolates come from children compared to $47 \%$ from adults and stool represents $81.9 \%$ of isolates.

Within this context, the increasing incidence of fluoroquinolone resistance in Salmonella spp. is of great concern. The resistance rate is higher among $S$. Typhimurium isolates (41.3\%) compared with $S$. Enteritidis (27.5\%). This result is in good agreement with previous data reported by Ricci \& Piddock (2009), who found that $S$. Typhimurium are generally more often resistant than S.Enteritidis but contrasts with data obtained by Marimón et al. (2004), who stated that nalidixic acid resistance in $S$. Enteritidis was more frequent than in $S$. Typhimurium (18.1 versus $3.0 \%$ ).

The MIC breakpoints for the fluoroquinolone used in the study are much higher than those recommended by CLSI (2008) and strains resistant to one fluoroquinolone prove to be resistant to all other fluoroquinolones. The present results are in agreement in resistance effect but higher in percentage with the results obtained by Rotimi et al. (2008), who showed that the resistance rates in Kuwait and United Arab Emirates for ciprofloxacin are 1.2\% and $0.8 \%$. Yang et al. (2011) studied the resistance of 30 Salmonella isolates to seven antibiotics and found that all (i.e. 100\%) are resistant to nalidixic acid while $96.7 \%$ were resistant to difloxacin, $93.3 \%$ were resistant to sarafloxacin, $73.3 \%$ were resistant to enrofloxacin, $66.7 \%$ were resistant to ciprofloxacin and gatifloxacin and $13.3 \%$ were resistant to levofloxacin.

The combination of fluoroquinolones with $\beta$-lactams is an attractive alternative to the classic combination of aminoglycosides and $\beta$-lactams antibiotics in the empiric treatment of serious infections (Maiche \& Teerenhovi, 1991). The combination of ciprofloxacin with $\beta$ - lactams antibiotic can be synergistic (Gould et al., 1997).

Egypt. J. Microbiol. 48 (2013) 
Time-kill curve experiments are frequently used to assess the activity of antimicrobial combination in vitro; however, the numbers of antimicrobial combinations that can be tested are limited. Therefore, we used the dynamic checkerboard method as a screen to determine the pertinent antibiotic concentration to be tested by the time-kill curve (Jacqueline et al., 2005).

In the treatment of enteric fever, gentamycin alone is avoided considering its low intracellular concentration and the survival of Salmonella inside macrophages, so gentamycin is used with fluoroquinolones derivatives. In this study gentamycin achieved synergistic action in combination with fluoroquinolones, these results are in line with Mandal et al. (2003) who show that ciprofloxacin in combination with gentamycin using the time-kill method has a $2.64 \log _{10}$ decrease in cfu/ml against one isolate.

From the $\beta$-lactams group, the third-generation cephalosporin (cefotaxime) retained high activity and continues to be an important agent treating enteric Salmonella species; therefore, cefotaxime is chosen for timekill synergy. Kim et al. (2010) stated that in combination therapy, ciprofloxacin with cefotaxime might be the treatment of choice for patients with typhoid fever; they confirm this by the time-kill technique. The combination of ciprofloxacin and cefotaxime against all three nalidixic acid resistant $S$. Typhi strains and one nalidixic acid-susceptible $S$. Typhi ATCC 9992 strain is significantly more effective in vitro in reducing bacterial counts by $\geq 3 \log _{10} \mathrm{cfu} / \mathrm{ml}$ at $24 \mathrm{~h}$ and shows synergistic effects (Kim et al., 2010). Cefotaxime and ciprofloxacin in combination may be considered as an option for difficult-to-treat salmonellosis (Chang et al., 2006).

The antagonism action achieved in the time-kill combination may be explained as follows: A large proportion of the bacterial population may be affected by antibiotic, with resultant death, but some cells may remain viable because: (i) They are in a different growth stage and less susceptible; (ii) The concentration of antibiotics is not sufficient to reach the intracellular levels required to effect the death of all the cells in the culture; or (iii) Resistance emerges. The same discrepancy has been encountered with $P$. aeruginosa as reported by Cappelletty \& Rybak (1996).

\section{Conclusion}

The fluoroquinolone resistant human Salmonella infections have markedly increased and to overcome this problem we used a combination therapy. Fluroquinolone combination with $\beta$-lactams (gentamycin, amikacin) and aminoglycosides (cefotaxime) were effective in the treatment of resistant Salmonella Typhimurium, $S$. Enteritidis and Typhi. 


\section{References}

Aktas, Z., Day, M., Kayacan, C.B., Diren, S. and Threlfall, E.J. (2007) Molecular characterization of $S$. Typhimurium and $S$. Enteritidis by plasmid analysis and pulsedfield gel electrophoresis. International Journal of Antimicrobial Agents, 30, 541-545.

AL-Dawodi, R., Farraj, M.A. and Essawi, T. (2012) Antimicrobial resistance in nontyphi Salmonella enterica isolated from humans and poultry in Palestine. The Journal of Infection in Developing Countries. 6(2), 132-136.

Ayana, N. and Surekha, K. (2008) Antimicrobial susceptibility pattern and characterization of ciprofloxacin resistant S. Typhi. Research Journal Microbiology, 3(11), 654-660.

Baucheron, S., Chaslus-Dancla, E. and Cloeckaert, A. (2004) Role of TolC and parC mutation in high-level fluoroquinolone resistance in Salmonella enterica serotype Typhimurium DT204. Journal of Antimicrobial Chemotherapy, 53, 657-659.

Brenner, D.J. and Farmer, J.J. III. (2004) Family I. Enterobacteriaceae. In: "Bergey's Manual of Systemic Bacteriology”, Brenner D.J., Krieg, N.R., Staley, J.T., Garrity, G.M., Boone, D.V., De Vos, P., Goodfellow, M., Rainey, F.A. and Schleifer, K.H. (Ed.), $2^{\text {nd }}$. Springer, USA.

Cappelletty, D.M. and Rybak, M.J. (1996) Comparison of methodologies for synergism testing of drug combination against resistant strains of $P$. aeruginosa. Antimicrobial Agents and Chemotherapy, 40, 677-683.

Chang, C.M., Lee, H.C., Lee, N.Y., Huang, G.C., Lee, I.W. and Ko., W.C. (2006) Cefotaxime-Ciprofloxacin combination therapy for nontyphoidal Salmonella bacteremia and paravertebral abscess after failure of monotherapy. Pharmacotherapy, 26 (11), 1671-1674.

Clinical and Laboratory Standards Institute (CLSI) (2008) Performance standard for antimicrobial susceptibility testing; Eighteen Information Supplement Document M100-S18.8, (1) Wayne, PA.

Eliopoulos, G.M. and Moellering, R.C. (1991) Antimicrobial combinations. In: "Antibiotics in Laboratory Medicine", V. Lorian (Ed.), $3^{\text {rd }}$ ed. The Williams \& Wilkinins Co. Baltimore, Maryland, USA.

Gordon, M.A. (2008) Salmonella infections in immunocompromised adults. Journal of Infection, 56, 413-422.

Gould, I.M., Wilson, D., Milne, K., Paterson, A., Golder, D. and Russell, D. (1997) In vitro pharmacodynamics studies of piperacillin/tazobactam with gentamycin and ciprofloxacin. Journal of Antimicrobial Chemotherapy, 39, 53-61.

Hakanen, A., Kotilainen, P., Huovinen, P., Helenius, H. and Siitonen, A. (2001) Reduced fluoroquinolone susceptibility in Salmonella enterica serotypes in travellers returning from Southeast Asia. Emerging Infectious Diseases, 7, 996-1003.

Egypt. J. Microbiol. 48 (2013) 
Hakanen, A., Kotilainen, P., Pitkanen, S., Huikko, S., Anja Siitonen, A. and Huovinen, P. (2006) Reduction in fluoroquinolone susceptibility among non-typhodial strains of Salmonella enterica isolated from Finnish patients. Journal of Antimicrobial Chemotherapy, 57, 569-572.

Hirose, K., Hashimoto, A., Tamura, K., Kawamura, Y., Ezaki, T., Sagara, H. and Watanabe, H. (2002) DNA sequence analysis of DNA gyrase and DNA topoisomerase IV quinolone resistance-determining regions of Salmonella enterica serovar Typhi and serovar Paratyphi A. Antimicrobial Agents and Chemotherapy, 46(10), 3249-3252.

Jacqueline, C., Navas, D. and Batard, E. (2005) In vitro and in vivo synergistic activities of linezolid combined with subinhibitory concentrations of imipenem against methicillin-resistant Staphylococcus aureus. Antimicrobial Agents and Chemotherapy, 49, 45-51.

Kim, D.M., Neupane, G.P., . Jang, S.J., Kim, S.H. and Lee, B.K. (2010) In vitro efficacy of the combination of ciprofloxacin and cefotaxime against nalidixic acidresistant Salmonella enterica serotype Typhi. International Journal of Antimicrobial Agents, 36(2), 155-158.

Lunguya, O., Lejon, V., Phoba, M.F., Bertrand, S., Vanhoof, R., Glupczynski, Y., Verhaegen, J., Tamfum, J.J.M. and Jacobs, J. (2013) Antimicrobial Resistance in Invasive Non-typhoid Salmonella from the Democratic Republic of the Congo: Emergence of Decreased Fluoroquinolone Susceptibility and Extended-spectrum Beta Lactamases. PLOS Neglected Tropical Diseases | www.plosntds.org, 7 (3), 1-9.

Maiche, A.G. and Teerenhovi, L. (1991) Empiric treatment of serious infections in patients with cancer: randomized comparison of two antibiotics. Infection, 19 (Suppl.6), S326-S329.

Mandal, S., Mandal, M.D. and Pal, N.K. (2003) Combination effect of ciprofloxacin and gentamycin against clinical isolates of Salmonella Typhi with reduced susceptibility to ciprofloxacin. Japanese Journal of Infectious Diseases, 56(4), 156157.

Marimón, J.M., Gomáriz, M., Zigorraga, C., Cilla, G. and Pérez-Trallero, E. (2004) Increasing prevalence of quinolone resistance in human nontyphoid Salmonella enterica isolates obtained in Spain from 1981 to 2003. Antimicrobial Agents and Chemotherapy, 48(10), 3789-3793.

Popoff, M.Y. (2001) Antigenic Formulas of the Salmonella serovars, Report of the WHO Collaborating Center for Reference and Research on Salmonella, $8^{\text {th }}$ ed. WHO.

Popoff, M.Y. and Le Minor, L. (1997) Antigenic formula of Salmonella serovars. Report of WHO. Collaborating Center for Reference and Research on Salmonella, Institute Pasteur, Paris, France.

Ricci, V. and Piddock, L.J.V. (2009) Ciprofloxacin selects for multidrug resistance in Salmonella enterica serovar Typhimurium mediated by at least two different pathways. Journal of Antimicrobial Chemotherapy, 63, 909-916. 
Rotimi, V.O., Jamala, W., Palb, T., Sonnevendb, A., Dimitrove, T.S. and Alberta, M.J. (2008) Emergence of multidrug-resistant Salmonella spp. and isolates with reduced susceptibility to ciprofloxacin in Kuwait and the United Arab Emirates. Diagnostic Microbiology and Infectious Disease, 60, 71-77.

Rybak, M.J. and McGrath, B.J. (1996) Combination antimicrobial therapy for bacterial infections. Guidelines for the clinician. Drugs, 52, 390-405.

Satish, K.P., Robert, C.M.J. and George, M.E. (2005) Multidrug-resistant urinary tract isolates of Escherichia coli from Ribeirao Preto, Sao Paulo, Brazil. Brazilian Journal of Infectious Diseases, 11, 575-578.

Thompson, R.B. and Miller, J.M. (2003) Specimen collection, transport and processing: bacteriology, pp. 286-330. In: "Manual of Clinical Microbiology”, Murray P.R., Baron, E.J., Jorgensen, J.H., Pfaller, M.A. and Yolken, R.H. (Ed.), $8^{\text {th }}$ ed. American Society for Microbiology, Washington, D.C.

Wedel, S.D., Bender, J.B., Leano, F.T., Boxrud, D.J., Hedberg, C. and Smith, K. (2005) Antimicrobial drug susceptibility of human and animal $S$. Typhimurium, Minnesota, 1997-2003. Emerging Infectious Diseases, 11, 1899-1906.

White, R., Burgess, D. and Manduru, M. (1996) Comparison of three different in vitro methods of detecting synergy: time-kill, checkerboard, and E test. Antimicrobial Agents and Chemotherapy, 40, 1914-1918.

Yang, B., Xi, M., Cui, S., Zhang, X., Shen, J., Sheng, M., Qu, D., Wang, X. and Meng, J. (2011) Mutations in gyrase and topoisomerase genes associated with fluoroquinolone resistance in Salmonella serovar from retail meats. Food Research International, 45 (2), 935-939. 


\section{توليفة من مضادات حيوية مختلفة ضد سالمونيلا إنتيريكا المقاومة}

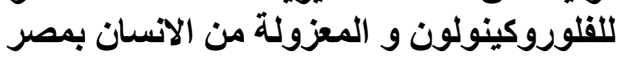

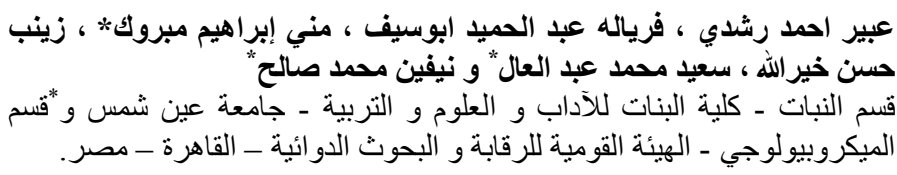

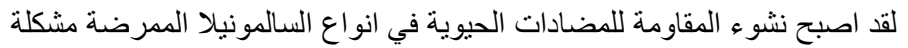

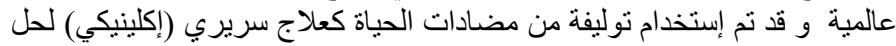

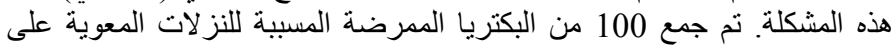

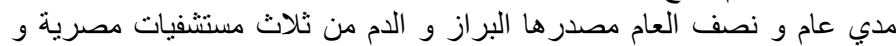

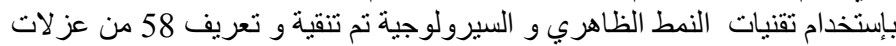

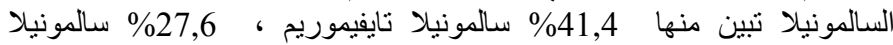

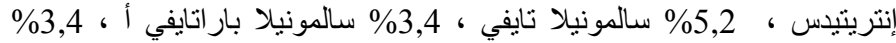

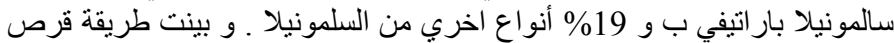

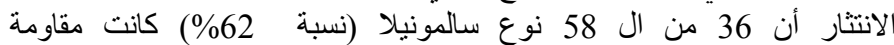

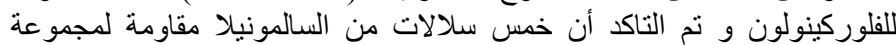

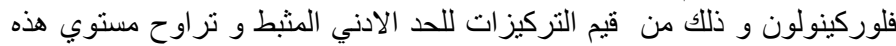

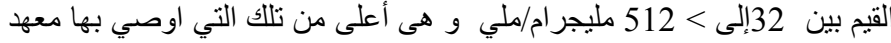
القباسات الطبية و المعلية (CLSI) و قد نم إجرية أجراء 75 معايرة دقيقة مشتركة بطريقة الثطرنج (combined microtitre cheackerboard) علي سلاءلات السالمونيلا الخمس ذات المقاومة المتعددة للفلوركينولون لتون التقدير إمكانية المعالجة

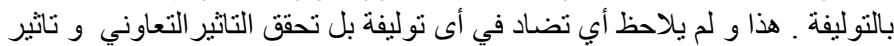

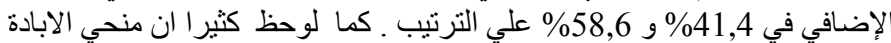

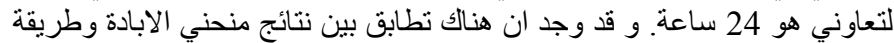

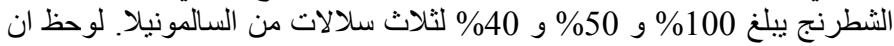

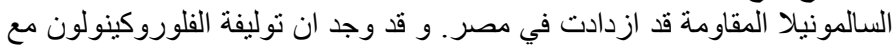

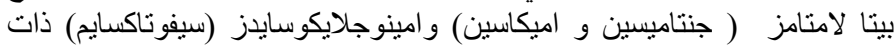

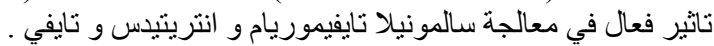

